\title{
Re-Evaluation of Clinical Dementia Diagnoses with Pittsburgh Compound B Positron Emission Tomography
}
M. Degerman Gunnarsson ${ }^{a}$
M. Lindau ${ }^{a, c}$
A.F. Santillod
A. Wall ${ }^{b}$
H. Engler ${ }^{f}$
L. Lannfelt ${ }^{a}$
H. Basun ${ }^{a}$ e
L. Kilander ${ }^{a}$

a Department of Public Health/Geriatrics and ${ }^{\mathrm{b}}$ Section of Nuclear Medicine and PET, Department of Radiology, Oncology and Radiation Sciences, Uppsala University, Uppsala, 'Department of Psychology, Stockholm University, Stockholm, d Geriatric Psychiatry, Department of Clinical Medicine, Lund University, Lund, and ${ }^{e}$ BioArctic Neuroscience AB, Stockholm, Sweden; ${ }^{f}$ Faculty of Medicine and Faculty of Science, University of the Republic Uruguay, Montevideo, Uruguay

\section{Key Words}

Alzheimer's disease - Dementia with Lewy bodies - Frontotemporal dementia - $\beta$-Amyloid · Amyloid biomarker - Pittsburgh compound B positron emission tomography $\cdot\left[{ }^{18} \mathrm{~F}\right]$ Fluoro2-deoxy-D-glucose positron emission tomography · Neuropsychological tests - Trail Making Test, part A - Episodic memory

\section{Abstract}

Objectives: There is an overlap regarding Pittsburgh compound $B$ (PIB) retention in patients clinically diagnosed as Alzheimer's disease $(A D)$ and non-AD dementia. The aim of the present study was to investigate whether there are any differences between PIB-positive and PIBnegative patients in a mixed cohort of patients with neurodegenerative dementia of mild severity regarding neuropsychological test performance and regional cerebral glucose metabolism measured with $\left[{ }^{18} \mathrm{~F}\right]$ fluoro-2-deoxy-D-glucose (FDG) positron emission tomography (PET). Methods: Eighteen patients clinically diagnosed as probable AD or frontotemporal dementia were examined with PIB PET, FDG PET and neuropsychological tests and followed for 5-9 years in a clinical setting. Results: The PIB-positive patients (7 out of 18) had slower psychomotor speed and more impaired visual episodic memory than the PIB-negative patients; otherwise performance did not differ between the groups. The initial clinical diagnoses were changed in one third of the patients (6 out of 18 ) during follow-up. Conclusions: The subtle differences in neuropsychological performance, the overlap of hypometabolic patterns and clinical features between $A D$ and non-AD dementia highlight the need for amyloid biomarkers and a readiness to re-evaluate the initial diagnosis. 
Degerman Gunnarsson et al.: Re-Evaluation of Clinical Dementia Diagnoses with Pittsburgh Compound B Positron Emission Tomography

\section{Introduction}

Alzheimer's disease (AD) is characterised by gradual-onset and slowly progressive decline of memory, language, praxis, perception, logical thinking and executive function [1, 2]. Decline in episodic memory is an early symptom in $\mathrm{AD}$ [3], but as the disease progresses, all memory systems deteriorate, including short-term memory, semantic memory and procedural memory. However, AD varies widely in clinical course and rate of cognitive decline [4-6]. There is a significant proportion of AD cases identified using strict clinical diagnostic criteria that show non-AD pathology, most commonly dementia with Lewy bodies (DLB) but also frontotemporal dementia (FTD) or other dementia disorders [7]. Reductions in regional cerebral glucose metabolism (rCMRglu) measured with [ $\left.{ }^{18} \mathrm{~F}\right]$ fluoro-2-deoxy-D-glucose (FDG) positron emission tomography (PET) reflect affected areas of the brain. AD is typically associated with hypometabolism in the posterior cingulate and parietotemporal cortices and in the frontal lobes in advanced disease [8]. In cohort studies with post mortem diagnosis on AD and non-AD dementia patients, FDG PET identified the AD cases with a sensitivity of about $90 \%$ and a specificity of $80 \%$ [9]. There is a large overlap in the clinical features, structural and functional imaging between different dementia disorders, and it is sometimes a challenge for the clinician to differentiate ante mortem between AD and non-AD dementia disorders. The clinical diagnosis of probable $\mathrm{AD}$ according to current diagnostic criteria has a sensitivity of approximately $80 \%$ and a specificity of $70 \%[10]$.

Deposition of $\beta$-amyloid $(A \beta)$ in senile plaques is a key characteristic in $A D$ together with intraneuronal accumulation of neurofibrillary tangles. $\mathrm{N}$-methyl $\left[{ }^{11} \mathrm{C}\right] 2-(40$-methylaminophenyl)-6-hydroxybenzothiazole (Pittsburgh compound B; PIB) is an amyloid-binding PET tracer used to detect amyloid depositions in vivo in the human brain [11]. Enhanced PIB retention is believed to be an early event in $\mathrm{AD}$, and the uptake does not increase substantially as the disease deteriorates [12]. PIB retention is not specific for AD. Patients with DLB often have high cortical PIB binding, since senile plaques frequently accompany the $\alpha$-synuclein aggregations [13]. Further, even substantial proportions of cognitively healthy older subjects and patients with mild cognitive impairment are PIB positive (PIB+), especially APOE $\varepsilon 4$ carriers [14], probably indicating preclinical AD.

rCMRglu as measured by FDG PET as well as neuropsychological performance in PIB+ and PIB-negative (PIB-) patients, suffering from different neurodegenerative dementia disorders, are less well described. The aim of the present study was to address this topic and re-evaluate the clinical diagnoses after long-term follow-up.

\section{Methods}

\section{Study Design}

Eighteen outpatients at the Memory Clinic, Department of Geriatrics, Uppsala University Hospital, who previously had participated in trials with PIB PET and FDG PET scans during 2003-2007 and had evidence of neurodegenerative disease were included $[15,16]$. The study protocol received ethical committee's approval and all participants or their legally acceptable representatives provided written informed consent. At baseline, 10 of the patients were diagnosed as AD according to the NINCDS-ADRDA [1] and DSM-IV criteria [2], 6 patients were diagnosed as behavioural variant FTD (bvFTD) and 2 as semantic dementia (SD) according to Neary et al.'s criteria [17]. All patients had CT scans consistent with their clinical diagnosis. They were examined with PIB PET and FDG PET, and an experienced neuropsychologist carried out and assessed all neuropsychological investigations. Mini-Mental State Examination (MMSE) scores at baseline and follow-ups, last available dementia stage and diagnosis, 
Degerman Gunnarsson et al.: Re-Evaluation of Clinical Dementia Diagnoses with

Pittsburgh Compound B Positron Emission Tomography

and date of death were collected from medical records. All patients were followed for 5-9 years, or to death. DLB patients were diagnosed according to McKeith et al.'s criteria [18]. Unspecified dementia (dementia UNS) was defined as dementia (International Statistical Classification of Diseases-10; ICD-10) without fulfilling any specific dementia diagnosis despite a comprehensive evaluation.

\section{Positron Emission Tomography}

Patients were examined with radiotracers in the order PIB and FDG on the same day after at least a 4-hour fasting period before PET. The PET scans were performed using Siemens ECAT EXACT HR+ scanners (CTI PET Systems, Inc., with an axial field of view of $155 \mathrm{~mm}$, providing 63 contiguous $2.46-\mathrm{mm}$ slices with $5.6-\mathrm{mm}$ transaxial and 5.4-mm axial resolution). The orbitomeatal line was used to centre the subject's head. The scanner protocol for transmission, emission and reconstructions as well as tracer doses were the same as used in previous studies at Uppsala Imanet $[11,12]$. The subjects were given $238 \pm 31 \mathrm{MBq}$ of FDG and $238 \pm 71 \mathrm{MBq}$ of PIB. Production of FDG and PIB was carried out according to the standard good manufacturing process at Uppsala Imanet. Synthesis of PIB was performed by means of the method described previously [11].

All PET investigations were analysed using identical standardised regions of interest (ROIs) in the brain and each subject had its set of ROIs individually delineated. All scans were visually characterised as either PIB+ or PIB- by an experienced PIB PET radiologist. The set of ROIs applied for statistical analyses and data management has been described in detail in earlier studies $[15,16]$. The CMRglu values were normalised to the pons value (ROI/ref.). For PIB, the mean uptake values of the ROIs obtained in the late time interval (40-60 min) were normalised to the corresponding uptake in the cerebellar cortex, which was chosen as reference region (ROI/ref.) [19]. Scans were characterised as PIB+ both by visual inspection and by a mean ratio $>1.6 \mathrm{nCi} / \mathrm{ml}$, obtained by calculating a mean value of the following areas: the frontal, parietal, temporal and posterior cingulum (ROI/ref.). PIB- scans were also characterised both on visual inspection and by a mean ratio $<1.6 \mathrm{nCi} / \mathrm{ml}$ of the same areas (ROI/ ref.). This threshold value is based on the values from healthy controls (mean value +1 standard deviation) in previous studies [12]. Four FDG PET scans of PIB- FTD patients (2 bvFTD and 2 SD) were characterised by visual inspection only due to technical failure.

\section{Neuropsychological Protocol}

Fourteen psychometric tests were used to assess the following skills: logical thinking: Arithmetic [Wechsler Adult Intelligence Scale-Revised (WAIS-R) [20] and WAIS 3rd edition (WAIS-III)] [21]; verbal function: word fluency test (FAS), object naming (Boston Naming Test), Similarities (WAIS-R, WAIS-III) and Information (WAIS-R, WAIS-III); visuospatial function: Clock Drawing with pre-drawn clock faces according to Luria [22] and Block Design (WAIS-R, WAIS-III); psychomotor speed/attention: Trail Making Test, part A (TMT A) and Digit Span (WAIS-R, WAIS III) and memory: episodic verbal memory: Claeson-Dahl Test for Learning and Memory, 5 out of 10 trials with respect to the patients' limited learning capacity [23] and visual episodic memory: Rey-Osterrieth Complex Figure, immediate recall.

\section{Statistical Analyses}

Comparisons of data from the psychometric tests and rCMRglu between PIB+ and PIBpatients were performed by the Mann-Whitney U test. Since some of the participants in the study were assessed with the WAIS-R and others with the WAIS-III, quotas were calculated in order to be able to compare the results. The quotas were calculated as obtained score on the subtest divided by the total possible test score on the subtest. The analyses of correlations between FDG PET data, PIB PET data and neuropsychological test results were conducted 
Table 1. Baseline characteristics

\begin{tabular}{|c|c|c|c|c|c|c|c|}
\hline $\begin{array}{l}\text { Pa- } \\
\text { tient } \\
\text { No. }\end{array}$ & $\begin{array}{l}\text { Gen- } \\
\text { der }\end{array}$ & $\begin{array}{l}\text { Age at } \\
\text { baseline, } \\
\text { years }\end{array}$ & $\begin{array}{l}\text { Education, } \\
\text { years }\end{array}$ & $\begin{array}{l}\text { PIB } \\
\text { retention }{ }^{a}\end{array}$ & CT: atrophy & $\begin{array}{l}\text { FDG PET: } \\
\text { parietotemporal } \\
\text { hypometabolism }^{\mathrm{b}}\end{array}$ & $\begin{array}{l}\text { Baseline } \\
\text { clinical } \\
\text { diagnosis }\end{array}$ \\
\hline 1 & $\mathrm{f}$ & 73 & 14 & + & temporal atrophy, bilateral & + & $\mathrm{AD}$ \\
\hline 2 & $\mathrm{~m}$ & 69 & 14 & + & mild frontotemporal atrophy, bilateral & + & $\mathrm{AD}$ \\
\hline 3 & $\mathrm{~m}$ & 66 & 15 & + & within normal limits & + & AD \\
\hline 4 & $\mathrm{~m}$ & 70 & 7 & + & mild temporal atrophy, bilateral & + & $\mathrm{AD}$ \\
\hline 5 & $\mathrm{~m}$ & 74 & 15 & + & within normal limits & + & $\mathrm{AD}$ \\
\hline 6 & $\mathrm{~m}$ & 69 & 15 & + & within normal limits & + & $\mathrm{AD}$ \\
\hline 7 & $\mathrm{f}$ & 68 & 7 & + & mild frontal atrophy, bilateral & - & bvFTD \\
\hline 8 & $\mathrm{~m}$ & 67 & 12 & - & within normal limits & + & $\mathrm{AD}$ \\
\hline 9 & $\mathrm{~m}$ & 65 & 10 & - & within normal limits & - & $\mathrm{AD}$ \\
\hline 10 & $\mathrm{f}$ & 71 & 7 & - & frontoparietal atrophy, bilateral & + & $\mathrm{AD}$ \\
\hline 11 & $\mathrm{~m}$ & 78 & 12 & - & within normal limits & - & $\mathrm{AD}$ \\
\hline 12 & $\mathrm{~m}$ & 64 & 10 & - & prominent frontotemporal atrophy, bilateral & + & bvFTD \\
\hline 13 & $\mathrm{~m}$ & 60 & 18 & - & within normal limits & - & bvFTD \\
\hline 14 & $\mathrm{~m}$ & 72 & 8 & - & within normal limits & - & bvFTD \\
\hline 15 & $\mathrm{f}$ & 62 & 9 & - & moderate temporal atrophy, bilateral & + & SD \\
\hline 16 & $\mathrm{f}$ & 52 & 12 & - & mild frontal atrophy, bilateral & - & bvFTD \\
\hline 17 & $\mathrm{~m}$ & 71 & 7 & - & $\begin{array}{l}\text { temporal atrophy, most prominent on right } \\
\text { side }\end{array}$ & + & bvFTD \\
\hline 18 & $\mathrm{f}$ & 68 & 9 & - & unspecified mild atrophy & - & SD \\
\hline
\end{tabular}

a Scans were characterised as PIB+ both on visual inspection and by a mean ratio $>1.6 \mathrm{nCi} / \mathrm{ml}$ obtained by calculating a mean value of the following areas: the frontal, parietal, temporal and posterior cingulum (ROI/ref.). $\mathrm{b}$ Typical pattern of regional glucose metabolism in AD.

using Spearman coefficient of correlation. The $\alpha$ level was set to 0.05 . Adjustments for multiple comparisons were not made since this was an exploratory study with a small number of patients.

\section{Results}

Baseline characteristics are shown in table 1. The PIB+ and the PIB- groups were well matched concerning gender, age and performance on the MMSE. The median length of education was 4 years longer in the PIB+ subjects. One PIB- SD patient scored only 10 points on the MMSE, but was classified as having a mild dementia since she was still able to perform complex activities of daily living. Parietotemporal hypometabolism was present in 6 of 7 PIB+ and in 5 of 11 PIB- patients. During follow-up, the clinical diagnoses were changed in 6 patients out of which 3 patients were re-diagnosed from AD to DLB (table 2). Two of these patients were PIB- and had normal cerebrospinal fluid (CSF) $A \beta$, tau and p-tau at baseline. Another 2 PIB- patients with a baseline AD diagnosis had high CSF tau and p-tau, but normal levels of CSF A $\beta$. Autopsy confirmed the FTD diagnosis in 1 PIB- patient, AD diagnosis in 2 $\mathrm{PIB}+$ patients and DLB diagnosis combined with presence of senile plaques in another PIB+ patient.

PIB+ patients had significantly lower psychomotor speed measured by time to completion on TMT A compared to PIB- patients and more impaired visual episodic memory. The median score on verbal episodic memory was lower in the PIB+ group compared to the PIB-group, although not significantly. Otherwise, the results did not differ between groups (table 3 ).

rCMRglu was approximately $30 \%$ lower in the parietal cortices in PIB+ patients compared to PIB- patients, although not significantly. rCMRglu in the frontal and temporal cortices was similar in the two groups (table 4$)$. Patients with a long education ( $>10$ years) had more 
Table 2. Baseline diagnoses and follow-up data (5-9 years)

\begin{tabular}{|c|c|c|c|c|c|c|}
\hline $\begin{array}{l}\text { Patient } \\
\text { No. }\end{array}$ & $\begin{array}{l}\text { Baseline } \\
\text { clinical } \\
\text { diagnosis }^{\mathrm{a}}\end{array}$ & $\begin{array}{l}\text { Final clinical } \\
\text { diagnosis }\end{array}$ & $\begin{array}{l}\text { Dementia stage } \\
\text { at baseline } \\
\text { (MMSE score) }\end{array}$ & $\begin{array}{l}\text { Dementia stage } \\
1-2 \text { years } \\
\text { (MMSE score) }\end{array}$ & $\begin{array}{l}\text { Dementia stage } \\
3-5 \text { years } \\
\text { (MMSE score) }\end{array}$ & $\begin{array}{l}\text { Dementia stage } \\
\geq 6 \text { years } \\
\text { (MMSE score) }\end{array}$ \\
\hline 1 & $\mathrm{AD}+$ & $\mathrm{AD}^{\mathrm{b}}$ & Mi (23) & Mo (23) & Se (16) & $\dagger$ \\
\hline 2 & $\mathrm{AD}+$ & $\mathrm{AD}$ & Mi (24) & Mi (25) & Mo (16) & Mo (10) \\
\hline 3 & $\mathrm{AD}+$ & $\mathrm{DLB}^{\mathrm{b}}$ & Mi (27) & Mo (10) & Se $(-)$ & $\dagger$ \\
\hline 4 & $\mathrm{AD}+$ & $\mathrm{AD}^{\mathrm{b}}$ & Mi (22) & Mi (18) & Se (9) & $\dagger$ \\
\hline 5 & $\mathrm{AD}+$ & $\mathrm{AD}$ & Mi (28) & Mi (29) & $\operatorname{Mi}(26)$ & Mo (20) \\
\hline 6 & $\mathrm{AD}+$ & $\mathrm{AD}$ & Mi (19) & Mo (15) & - & - \\
\hline 7 & bvFTD + & dementia UNS & Mi (27) & Mi (23) & Mo (-) & Se $(-)$ \\
\hline 8 & $\mathrm{AD}-$ & DLB & Mi (30) & Mi (30) & Mi (24) & Mo (20) \\
\hline 9 & $\mathrm{AD}-$ & DLB & Mi (28) & Mo (22) & Se $(-)$ & + \\
\hline 10 & $\mathrm{AD}-$ & dementia UNS & Mi (28) & Mi (24) & Mi (23) & Mo (18) \\
\hline 11 & $\mathrm{AD}-$ & dementia UNS & Mi (23) & Mi (22) & Mo (20) & - \\
\hline 12 & bvFTD - & bvFTD & Mi (27) & Mi (29) & Mi (29) & $\operatorname{Mi}(-)$ \\
\hline 13 & bvFTD - & bvFTD & Mi (29) & $\operatorname{Mi}(-)$ & Mo $(-)$ & $\operatorname{Se}(-)$ \\
\hline 14 & bvFTD - & bvFTD & Mi (30) & Mi (29) & $\dagger$ & $\dagger$ \\
\hline 15 & SD - & SD & Mi (29) & Mi (22) & Mo (-) & Se $(-)$ \\
\hline 16 & bvFTD - & bvFTD & Mi (29) & Mi (30) & $\operatorname{Mi}(26)$ & $\operatorname{Mi~}(-)$ \\
\hline 17 & bvFTD - & bvFTD $^{b}$ & Mi (19) & Se $(-)$ & $\dagger$ & $\dagger$ \\
\hline 18 & SD - & SD & Mi (10) & Mo (-) & Se $(-)$ & $\dagger$ \\
\hline
\end{tabular}

$\mathrm{Mi}=$ Mild dementia $;$ Mo = moderate dementia $;$ Se $=$ severe dementia .

${ }^{\mathrm{a}}+$ or - indicate PIB+ or PIB-. ${ }^{\mathrm{b}}$ Diagnosis confirmed at autopsy. ${ }^{\dagger}$ Dead at follow-up.

Table 3. Neuropsychological test results in PIB+ and PIB- patients $(n=18)$

\begin{tabular}{|c|c|c|c|}
\hline Neuropsychological tests & $\mathrm{PIB}+(\mathrm{n}=7)$ & PIB- $(n=11)$ & $\mathrm{p}$ level \\
\hline \multicolumn{4}{|l|}{ Logical thinking } \\
\hline Arithmetic ${ }^{\mathrm{a}, \mathrm{b}}$ & $0.45(0.32-0.91)$ & $0.47(0.07-0.79)$ & 0.84 \\
\hline \multicolumn{4}{|l|}{ Verbal function } \\
\hline FAS $^{\mathrm{b}}$ & $34(3-56)$ & $26(3-39)$ & 0.29 \\
\hline Boston Naming Test ${ }^{\mathrm{b}}$ & $17.5(12-24)$ & $19(0-26)$ & 0.72 \\
\hline Information ${ }^{\mathrm{a}, \mathrm{b}}$ & $0.61(0.36-0.79)$ & $0.68(0.07-0.83)$ & 0.89 \\
\hline Similarities ${ }^{\mathrm{a}}$ & $0.42(0.03-0.76)$ & $0.33(0-0.81)$ & 0.62 \\
\hline \multicolumn{4}{|l|}{ Visuospatial function } \\
\hline Clock Drawing & $2.5(1.5-4)$ & $2(0.5-5)$ & 0.27 \\
\hline Block Design $^{\mathrm{a}}$ & $0.32(0.01-0.56)$ & $0.40(0.16-0.67)$ & 0.52 \\
\hline \multicolumn{4}{|l|}{ Psychomotor speed/attention } \\
\hline TMT A time to completion, $\mathrm{s}$ & $95(61-145)$ & $65(34-99)$ & $0.03^{*}$ \\
\hline Digit Span forward & $5(5-6)$ & $6(4-7)$ & 0.53 \\
\hline Digit Span backward & $4(2-6)$ & $4(0-6)$ & 0.38 \\
\hline \multicolumn{4}{|l|}{ Memory } \\
\hline Verbal episodic memory ${ }^{\mathrm{b}, \mathrm{c}}$ & $16(0-30)$ & $24(9-39)$ & 0.16 \\
\hline Visual episodic memory ${ }^{\mathrm{d}}$ & $0(0-4.5)$ & $9(0-25)$ & $0.04^{*}$ \\
\hline
\end{tabular}

Data are medians with ranges in parentheses. * Significant difference between PIB+ and PIB- patients, Mann-Whitney U test.

${ }^{\mathrm{a}}$ Test result quota (score/maximal score). ${ }^{\mathrm{b}}$ Seventeen patients due to missing data. ${ }^{\mathrm{c}}$ Claeson-Dahl's test.

${ }^{\mathrm{d}}$ Rey-Osterrieth Complex Figure memory. 
Table 4. Mean rCMRglu values in the pons in PIB+ and PIBpatients $(n=14)$

\begin{tabular}{lll}
\hline & PIB $+(\mathrm{n}=7)$ & PIB- $(\mathrm{n}=7)$ \\
\hline Frontal ctx dx & $1.34(1.03-1.51)$ & $1.46(1.01-1.66)$ \\
Frontal ctx sin & $1.36(1.12-1.50)$ & $1.54(1.03-2.09)$ \\
Parietal ctx dx & $1.05(0.93-1.59)$ & $1.54(0.72-1.76)$ \\
Parietal ctx sin & $1.13(0.88-1.55)$ & $1.59(0.74-1.81)$ \\
Temporal ctx dx & $0.92(0.88-1.23)$ & $1.06(0.74-1.39)$ \\
Temporal ctx sin & $0.97(0.84-1.21)$ & $1.15(1.00-1.39)$ \\
\hline
\end{tabular}

Data are medians with ranges in parentheses indicated as $\mu \mathrm{mol} /$ $\min / 100 \mathrm{ml} . \mathrm{ctx}=$ Cortex; $\mathrm{dx}=$ dexter; $\sin =$ sinister .

Table 5. Spearman rank order correlation between rCMRglu on FDG PET and neuropsychological tests in 14 patients

\begin{tabular}{|c|c|c|c|c|c|c|}
\hline Neuropsychological tests & $\begin{array}{l}\text { Fr ctx } \\
d x\end{array}$ & $\begin{array}{l}\text { Fr ctx } \\
\sin \end{array}$ & $\begin{array}{l}\text { Par ctx } \\
d x\end{array}$ & $\begin{array}{l}\text { Par ctx } \\
\text { sin }\end{array}$ & $\begin{array}{l}\text { Tmp ctx } \\
d x\end{array}$ & $\begin{array}{l}\text { Tmp ctx } \\
\sin \end{array}$ \\
\hline Arithmetic $^{\mathrm{a}}$ & 0.53 & 0.32 & $0.69^{* *}$ & 0.48 & 0.05 & 0.08 \\
\hline FAS $^{\mathrm{a}}$ & -0.02 & -0.11 & 0.03 & -0.10 & -0.20 & -0.46 \\
\hline Boston Naming Test ${ }^{\mathrm{a}}$ & 0.05 & 0.02 & 0.17 & 0.24 & 0.48 & 0.49 \\
\hline Information & 0.07 & -0.12 & 0.08 & 0.13 & 0.06 & -0.04 \\
\hline Similarities & 0.27 & 0.23 & $0.56^{*}$ & 0.47 & 0.17 & 0.33 \\
\hline Clock Drawing & -0.12 & -0.20 & -0.08 & -0.14 & 0.07 & -0.19 \\
\hline Block Design & 0.37 & 0.26 & 0.35 & 0.44 & -0.11 & 0.44 \\
\hline TMT A time to completion & $-0.56^{*}$ & -0.44 & $-0.62 *$ & $-0.66^{* *}$ & -0.14 & $-0.54^{*}$ \\
\hline Digit Span forward & 0.44 & 0.28 & 0.41 & 0.47 & 0.31 & 0.50 \\
\hline Digit Span backward & 0.22 & 0.18 & 0.40 & 0.26 & 0.09 & 0.23 \\
\hline Verbal episodic memory ${ }^{a}$, b & 0.51 & 0.39 & $0.66^{* *}$ & $0.61^{*}$ & 0.21 & 0.44 \\
\hline Visual episodic memory ${ }^{c}$ & 0.31 & 0.18 & 0.11 & 0.25 & 0.25 & 0.26 \\
\hline
\end{tabular}

ctx = Cortex; $\mathrm{dx}=$ dexter; fr = frontal; par = parietal; $\sin =$ sinister; tmp = temporal. ${ }^{*} \mathrm{p}<0.05 ;{ }^{* *} \mathrm{p}<0.01$.

a Thirteen patients due to missing data. ${ }^{\mathrm{b}}$ Claeson-Dahl's test. ${ }^{\mathrm{c}}$ Rey-Osterrieth Complex Figure memory.

pronounced hypometabolism in the temporal lobes and scored higher on Information, but did not differ in performance on any other psychometric test compared to subjects with a short education ( $\leq 10$ years) (data not shown).

Performances on Arithmetic and Similarities were both positively correlated with CMRglu in the right parietal cortex. Mental speed measured by time to complete TMT A was inversely correlated with CMRglu in the right and left parietal cortices, the right frontal cortex and the left temporal cortex. Performance on the verbal episodic memory test correlated with CMRglu in the right and left parietal cortices; otherwise, the test results did not differ between groups (table 5). Correlation analyses revealed no relations between PIB and rCMRglu.

\section{Discussion}

In this study, PIB+ dementia patients, i.e. with evidence of AD pathology consisting of fibrillised $A \beta$, were more impaired regarding psychomotor speed and visual episodic memory compared to PIB- dementia patients, in spite of a higher educational attainment. Poor perfor- 
mance on the TMT A time to completion is not exclusively seen in AD but is also seen in subjects with high age and low educational level [24] as well as in different psychiatric and other dementia disorders $[25,26]$. Our significant result is probably due to slower psychomotor speed in the AD patients compared to the FTD patients. Previous studies have shown conflicting results, with equal [27], worse [28-30] or better [31] performance on psychomotor speed tests in AD compared to FTD. The performance on TMT A differs between various subtypes of FTD, and patients with bvFTD seem to be faster than those with temporal variants, i.e. SD and progressive non-fluent aphasia [28]. Further, performance on TMT A also depends on disease stage. In one study, AD subjects in a group with more severe dementia performed better on TMT A compared with FTD, but were significantly slower than FTD patients in the mildly demented group (MMSE $\geq 20$ ) [32].

Impaired episodic memory is the most specific early symptom of $\mathrm{AD}$, and performance on memory tests differs from other neurodegenerative dementia disorders such as FTD [33] and DLB [34] on a group level. As expected, we could demonstrate a difference between PIB+ and PIB- patients in visual episodic memory and a tendency to a difference in verbal episodic memory. In contrast, results in tests assessing verbal function, arithmetic and visuospatial function were the same.

Parietal lobe lesions are associated with impaired object recognition and inability to use topographic information, dyscalculia, apraxia and right-left confusion. Our results are in concordance with the involvement of the parietal lobes in calculation, abstract verbal thinking, logical reasoning [35, 36] and processing numerical tasks as in the TMT [37]. They are also involved in episodic memory retrieval [38]. Performance on the TMT has mainly been linked to a left-sided frontal activation [39]. We found correlations between performance on TMT A and CMRglu in the frontal cortices, but without left-side dominance.

Although not significant, PIB+ patients had 30\% lower CMRglu in the parietal cortices compared to PIB- patients, i.e. the typical hypometabolic pattern in AD. As expected, there were no relations between PIB and rCMRglu due to the mixture of diagnoses and since PIB retention early reaches a plateau in $\mathrm{AD}$ [40]. There is a good correspondence between in vivo PIB PET and post mortem region-matched assessment of plaques [41]. Moreover, there is a high concordance between high PIB retention and low CSF A $\beta[16,42]$. However, high PIB retention is not exclusively seen in $\mathrm{AD}$ and is, for example, common in LBD [13], and 1 out of 3 LBD patients in our study was PIB+. Further, the proportion of PIB+ subjects increases with age, and about a third of cognitively healthy older volunteers have PIB+ scans [43], probably indicating preclinical AD. Consequently, the presence of biomarkers indicating brain amyloidosis should not be considered as a conclusive evidence of the cause of cognitive impairment in a dementia disorder [44].

Especially in the early stages of different dementia diseases, the assessment of the clinical diagnosis is a challenge. There are large variations in the cognitive profiles of AD dementia.

FTD sometimes presents similarly to AD with primarily impaired episodic memory and spatial disorientation [45]. The parkinsonism in LBD is not always prominent, and the patients and their caregivers do not always report either hallucinations or fluctuating attention. Other dementia disorders such as argyrophilic grain disease and neurofibrillary tangle-predominant dementia cause $5-10 \%$ of dementia in high age but are not possible to diagnose ante mortem [46-48]. Further, mixed pathologies are common in AD patients, especially among the oldest $[49,50]$. In the present study, the diagnosis was changed for 6 out of 18 patients after PIB PET, FDG PET and repeated clinical examinations, in accordance with previous studies $[51,52]$.

One obvious limitation of our study was the small number of patients, and larger studies would most likely identify more subtle differences between PIB + and PIB-patients concerning performance on psychometric tests and rCMRglu. Another limitation is that the design did not 
Degerman Gunnarsson et al.: Re-Evaluation of Clinical Dementia Diagnoses with Pittsburgh Compound B Positron Emission Tomography

allow adjustment for differences in educational level and degree of cognitive impairment. According to the cognitive reserve hypothesis, patients with a longer education cope better with pathologic changes in dementia because of a higher IQ and premorbid cognitive resources [53], and this probably interferes with the test performance in the present study. Further, although all patients had a mild dementia at baseline, further adjustments for differences in disease state were not possible.

In conclusion, we followed 18 patients with mild neurodegenerative, non-vascular dementia who underwent PIB PET, FDG PET and a neuropsychological test battery. The initial clinical diagnoses were changed during follow-up in one third of the patients. Immunotherapies for the $A \beta$ protein are under investigation at several sites all over the world, and the possibility of a specific $A \beta$ load-reducing treatment enhances the need for accurate diagnosis and detection of underlying AD pathology. The small differences in neuropsychological performance and the overlap of hypometabolic patterns on FDG PET and clinical features between different clinically diagnosed $A D$ and non- $A D$ dementias highlight the need for amyloid biomarkers (amyloid PET or CSF A $\beta$ ) and a readiness to re-evaluate the initial diagnosis.

\section{Acknowledgments}

This study was supported by grants from the Alzheimer's Association and Amersham Foundation. The authors thank the research nurse Christina Alm for assistance in the study.

\section{Disclosure Statement}

The authors report no conflict of interest.

\section{References}

1 McKhann G, Drachman D, Folstein M, Katzman R, Price D, Stadlan EM: Clinical diagnosis of Alzheimer's disease: report of the NINCDS-ADRDA Work Group under the auspices of Department of Health and Human Services Task Force on Alzheimer's Disease. Neurology 1984;34:939-944.

2 American Psychiatric Association: Diagnostic and Statistical Manual of Mental Disorders, ed 4. DSM-IV. Washington, American Psychiatric Association, 1994.

-3 Sarazin M, Berr C, De Rotrou J, Fabrigoule C, Pasquier F, Legrain S, Michel B, Puel M, Volteau M, Touchon J, Verny M, Dubois B: Amnestic syndrome of the medial temporal type identifies prodromal AD: a longitudinal study. Neurology 2007;69:1859-1867.

4 Iqbal K, Flory M, Khatoon S, Soininen H, Pirttila T, Lehtovirta M, Alafuzoff I, Blennow K, Andreasen N, Vanmechelen E, Grundke-Iqbal I: Subgroups of Alzheimer's disease based on cerebrospinal fluid molecular markers. Ann Neurol 2005;58:748-757.

5 Murray ME, Graff-Radford NR, Ross OA, Petersen RC, Duara R, Dickson DW: Neuropathologically defined subtypes of Alzheimer's disease with distinct clinical characteristics: a retrospective study. Lancet Neurol 2011;10:785-796.

6 Holmes C, Lovestone S: Long-term cognitive and functional decline in late onset. Alzheimer's disease: therapeutic implications. Age Aging 2003;32:200-204.

-7 Piguet 0, Halliday GM, Creasey H, Broe GA, Kril JJ: Frontotemporal dementia and dementia with Lewy bodies in a case-control study of Alzheimer's disease. Int Psychogeriatr 2009;21:688-695.

8 Mosconi L, Tsui WH, Herholz K, Pupi A, Drzezga A, Lucignani G, Reiman EM, Holthoff V, Kalbe E, Sorbi S, DiehlSchmid J, Perneczky R, Clerici F, Caselli R, Beuthien-Baumann B, Kurz A, Minoshima S, de Leon MJ: Multicenter standardized 18F-FDG PET diagnosis of mild cognitive impairment, Alzheimer's disease, and other dementias. J Nucl Med 2008;49:390-398.

-9 Bohnen NI, Djang DS, Herholz K, Anzai Y, Minoshima S: Effectiveness and safety of 18F-FDG PET in the evaluation of dementia: a review of the recent literature. J Nucl Med 2012;53:59-71. 
Degerman Gunnarsson et al.: Re-Evaluation of Clinical Dementia Diagnoses with Pittsburgh Compound B Positron Emission Tomography

10 Knopman DS, DeKosky ST, Cummings JL, Chui H, Corey-Bloom J, Relkin N, Small GW, Miller B, Stevens JC: Practice parameter: diagnosis of dementia (an evidence-based review). Neurology 2001;56:1143-1153.

11 Klunk WE, Engler H, Nordberg A, Wang Y, Blomqvist G, Holt DP, Bergström M, Savitcheva I, Huang GF, Estrada S, Ausén B, Debnath ML, Barletta J, Price JC, Sandell J, Lopresti BJ, Wall A, Koivisto P, Antoni G, Mathis CA, Långström B: Imaging brain amyloid in Alzheimer's disease with Pittsburgh Compound-B. Ann Neurol 2004;55: 306-319.

12 Engler H, Forsberg A, Almkvist O, Blomquist G, Larsson E, Savitcheva I, Wall A, Ringheim, A, Långström B, Nordberg A: Two-year follow-up of amyloid deposition in patients with Alzheimer's disease. Brain 2006;129: 2856-2866.

13 Gomperts SN, Rentz DM, Moran E, Becker JA, Locascio JJ, Klunk WE, Mathis CA, Elmaleh DR, Shoup T, Fischman AJ, Hyman BT, Growdon JH, Johnson KA: Imaging amyloid deposition in Lewy body diseases. Neurology 2008; 16:903-910.

14 Rowe CC, Ellis KA, Rimajova M, Bourgeat P, Pike KE, Jones G, Fripp J, Tochon-Danguy H, Morandeau L, O’Keefe G, Price R, Raniga P, Robins P, Acosta O, Lenzo N, Szoeke C, Salvado O, Head R, Martins R, Masters CL, Ames D, Villemagne VL: Amyloid imaging results from the Australian Imaging, Biomarkers and Lifestyle (AIBL) study of aging. Neurobiol Aging 2010;31:1275-1283.

-15 Santillo AF, Skoglund L, Lindau M, Eeg-Olofsson KE, Tovi M, Engler H, Brundin RM, Ingvast S, Lannfelt L, Glaser A, Kilander L: In vivo amyloid imaging with PET in frontotemporal dementia. Eur J Nucl Med Mol Imaging 2008;35:100-106.

-16 Degerman Gunnarsson M, Lindau M, Wall A, Blennow K, Darreh-Shori T, Basu S, Nordberg A, Larsson A, Lannfelt L, Basun H, Kilander L: Pittsburgh compound-B and Alzheimer's disease biomarkers in CSF, plasma and urine: an exploratory study. Dement Geriatr Cogn Disord 2010;29:204-212.

-17 Neary D, Snowden JS, Gustafson L, Passant U, Stuss D, Black S, Freedman M, Kertesz A, Robert PH, Albert M, Boone K, Miller BL, Cummings J, Benson DF: Frontotemporal lobar degeneration: a consensus on clinical diagnostic criteria. Neurology 1998;51:1546-1554.

-18 McKeith IG, Dickson DW, Lowe J, Emre M, O’Brien JT, Feldman H, Cummings J, Duda JE, Lippa C, Perry EK, Aarsland D, Arai H, Ballard CG, Boeve B, Burn DJ, Costa D, Del Ser T, Dubois B, Galasko D, Gauthier S, Goetz CG, Gomez-Tortosa E, Halliday G, Hansen LA, Hardy J, Iwatsubo T, Kalaria RN, Kaufer D, Kenny RA, Korczyn A, Kosaka K, Lee VM, Lees A, Litvan I, Londos E, Lopez OL, Minoshima S, Mizuno Y, Molina JA, Mukaetova-Ladinska EB, Pasquier F, Perry RH, Schulz JB, Trojanowski JQ, Yamada M, Consortium on DLB: Diagnosis and management of dementia with Lewy bodies: third report of the DLB Consortium. Neurology 2005;65:1863-1872.

-19 Forsberg A, Engler H, Almkvist O, Blomquist G, Hagman G, Wall A, Ringheim A, Långström B, Nordberg A: PET imaging of amyloid deposition in patients with mild cognitive impairment. Neurobiol Aging 2008;29:14561465.

20 Bartfai A, Nyman H, Stegmann B: Wechsler Adult Intelligence Scale - Revised: Manual (in Swedish). Stockholm, Psykologiforlaget, 1994.

21 Wechsler D: Wechsler Adult Intelligence Scale, ed 3. Swedish version. Stockholm, Harcourt Assessment, 2003.

22 Christensen AL: Luria's Neuropsychological Investigation, ed 2. Risskov, Munksgaard, 1984.

23 Claeson LE, Esbjörnsson E, Tännérus BM, Wahlbin M: Claeson-Dahls test för inlärning och minne, rev. Halmstad, The Halmstad Printer, 2003.

24 Ashendorf L, Jefferson AL, O'Connor MK, Chaisson C, Green RC, Stern A: Trail Making Test errors in normal aging, mild cognitive impairment, and dementia. Arch Clin Neuropsychol 2008;23:129-137.

25 Mahurin RK, Velligan DI, Hazleton B, Mark Davis J, Eckert S, Miller AL: Trail making test errors and executive function in schizophrenia and depression. Clin Neuropsychol 2006;20:271-288.

-26 Bailon O, Roussel M, Boucart M, Krystkowiak P, Godefroy O: Psychomotor slowing in mild cognitive impairment, Alzheimer's disease and Lewy body dementia: mechanisms and diagnostic value. Dement Geriatr Cogn Disord 2010;20:388-396.

-27 Heidler-Gary J, Gottesman R, Newhart M, Chang S, Ken L, Hillis AE: Utility of behavioral versus cognitive measures in differentiating between subtypes of frontotemporal lobar degeneration and Alzheimer's disease. Dement Geriatr Cogn Disord 2007;23:184-193.

28 Libon DJ, Xie SX, Moore P, Farmer J, Antani S, McCawley G, Cross K, Grossman M: Patterns of neuropsychological impairment in frontotemporal dementia. Neurology 2007;30:369-375.

-29 Giovagnoli AR, Erbetta A, Reati F, Bugiani O: Differential neuropsychological patterns of frontal variant frontotemporal dementia and Alzheimer's disease in a study of diagnostic concordance. Neuropsychologia 2008; 46:1495-1504.

30 Stopford CL, Thompson JC, Neary D, Richardson AM, Snowden JS: Working memory, attention, and executive function in Alzheimer's disease and frontotemporal dementia. Cortex 2012;48:429-446.

-31 Walker AJ, Meares S, Sachdev PS, Brodaty H: The differentiation of mild frontotemporal dementia from Alzheimer's disease and healthy aging by neuropsychological tests. Intern Psychogeriatr 2005;17:57-68.

-32 Castiglioni S, Pelati O, Zuffi M, Somalvico F, Marino L, Tentorio T, Franceschi M: The frontal assessment battery does not differentiate frontotemporal dementia from Alzheimer's disease. Dement Geriatr Cogn Disorder 2006;22:125-131.

-33 Wicklund AH, Johnson N, Rademaker A, Weitner BB, Weintraub S: Word list versus story memory in Alzheimer disease and frontotemporal dementia. Alzheimer Dis Assoc Disord 2006;20:86-92. 
-34 Walker Z, Allen RL, Shergill S, Katona CL: Neuropsychological performance in Lewy body dementia and Alzheimer's disease. Br J Psychiatry 1997;170:156-158.

35 Dehaene S, Molko N, Cohen L, Wilson AJ: Arithmetic and the brain. Curr Opin Neurobiol 2004;14:218-224.

-36 Woo BK, Harwood DG, Melrose RJ, Mandelkern MA, Campa OM, Walston A, Sultzer DL: Executive deficits and regional brain metabolism in Alzheimer's disease. Int J Geriatr Psychiatry 2009;25:1150-1158.

-37 Fias W, Lammertyn J, Caessens B, Orban GA: Processing of abstract ordinal knowledge in the horizontal segment of the intraparietal sulcus. J Neurosci 2007;15:8952-8956.

-38 Berryhill ME, Phuong L, Picasso L, Cabeza R, Olson IR: Parietal lobe and episodic memory: bilateral damage causes impaired free recall of autobiographical memory. J Neurosci 2007;26:14415-14423.

-39 Moll J, de Oliveira-Souza R, Moll FT, Bramati IE, Andreiuolo PA: The cerebral correlates of set-shifting: an fMRI study of the trail making test. Arq Neuropsiquiatr 2002;60:900-905.

-40 Edison P, Archer HA, Hinz R, Hammers A, Pavese N, Tai YF, Hotton G, Cutler D, Fox N, Kennedy A, Rossor M, Brooks DJ: Amyloid, hypometabolism, and cognition in Alzheimer disease: an [11C]PIB and [18F]FDG PET study. Neurology 2007;13:501-508.

41 Driscoll I, Troncoso JC, Rudow G, Sojkova J, Pletnikova O, Zhou Y, Kraut MA, Ferrucci L, Mathis CA, Klunk WE, O’Brien RJ, Davatzikos C, Wong DF, Resnick SM: Correspondence between in vivo (11)C-PiB-PET amyloid imaging and postmortem, region-matched assessment of plaques. Acta Neuropathol 2012;124:823-831.

42 Grimmer T, Riemenschneider M, Förstl H, Henriksen G, Klunk WE, Mathis CA, Shiga T, Wester HJ, Kurz A, Drzezga A: Beta amyloid in Alzheimer's disease: increased deposition in brain is reflected in reduced concentration in cerebrospinal fluid. Biol Psychiatry 2009;65:927-934.

-43 Pike KE, Ellis KA, Villemagne VL, Good N, Chételat G, Ames D, Szoeke C, Laws SM, Verdile G, Martins RN, Masters CL, Rowe CC: Cognition and beta-amyloid in preclinical Alzheimer's disease: data from the AIBL study. Neuropsychologia 2011;49:2384-2390.

-44 Caso F, Gesierich B, Henry M, Sidhu M, LaMarre A, Babiak M, Miller BL, Rabinovici GD, Huang EJ, Magnani G, Filippi M, Comi G, Seeley WW, Gorno-Tempini ML: Nonfluent/agrammatic PPA with in-vivo cortical amyloidosis and Pick's disease pathology. Behav Neurol 2013;26:95-106.

45 Pennington C, Hodges JR, Hornberger M: Neural correlates of episodic memory in behavioral variant frontotemporal dementia. J Alzheimers Dis 2011;24:261-268.

-46 Beach TG, Monsell SE, Phillips LE, Kukull W: Accuracy of the clinical diagnosis of Alzheimer disease at National Institute on Aging Alzheimer Disease Centers, 2005-2010. J Neuropathol Exp Neurol 2012;71:266-273.

47 Ferrer I, Santpere G, van Leeuwen FW: Argyrophilic grain disease. Brain 2008;131:1416-1432.

48 Jellinger KA, Attems J: Neurofibrillary tangle-predominant dementia: comparison with classical Alzheimer disease. Acta Neuropathol 2007;113:107-117.

-49 Takeuchi J, Shimada H, Ataka S, Kawabe J, Mori H, Mizuno K, Wada Y, Shiomi S, Watanabe Y, Miki T: Clinical features of Pittsburgh compound-B-negative dementia. Dement Geriatr Cogn Disord 2012;34:112-120.

50 James BD, Bennett DA, Boyle PA, Leurgans S, Schneider JA: Dementia from Alzheimer disease and mixed pathologies in the oldest old. JAMA 2012;307:1798-1800.

51 Ossenkoppele R, Prins ND, Pijnenburg YA, Lemstra AW, van der Flier WM, Adriaanse SF, Windhorst AD, Handels RL, Wolfs CA, Aalten P, Verhey FR, Verbeek MM, van Buchem MA, Hoekstra OS, Lammertsma AA, Scheltens $\mathrm{P}$, van Berckel BN: Impact of molecular imaging on the diagnostic process in a memory clinic. Alzheimers Dement 2013;9:414-421.

52 Frederiksen KS, Hasselbalch SG, Hejl AM, Law I, Højgaard L, Waldemar G: Added diagnostic value of (11)C-PiBPET in memory clinic patients with uncertain diagnosis. Dement Geriatr Cogn Dis Extra 2012;2:610-621.

53 Stern Y, Alexander GE, Prohovnik I, Mayeux R: Inverse relationship between education and parietotemporal perfusion deficit in Alzheimer's disease. Ann Neurol 1992;32:371-375. 